\title{
O uso das tecnologias educacionais e as metodologias de ensino utilizadas
}

O desenvolvimento desse artigo tem por objetivo discutir e trazer à tona o uso das novas tecnologias educacionais e, por conseguinte, as metodologias de ensino utilizadas. Dessa forma, pretende-se estabelecer um paralelo entre tais tecnologias e as metodologias de ensino empregadas, para que possamos perceber se houve um desenvolvimento igualitário ou se ambas estão em defasagem, ou seja, os métodos de ensino empregados na sala de aula, atualmente, conseguem assimilar e acompanhar o avanço das tecnologias? Essa discussão acerca das tecnologias como meios didáticos na educação é de extrema importância, porém nem sempre a escola consegue acompanhar as evoluções tecnológicas. Mas, portanto, as tecnologias fazem parte do contexto atual e deve ser utilizada de forma favorável à educação. O presente artigo pretende demostrar a importância da utilização das tecnologias da comunicação na educação em busca de melhores resultados de aprendizagens. A pesquisa também traz à tona reflexões sobre a utilização das tecnologias, e críticas construtivas em relação à inserção da inovação tecnológica sem formação para os profissionais da educação. Dessa forma, o professor, que é ator importante nesse processo educacional tecnológico, e está diretamente envolvido com o aluno no processo de ensino e aprendizagem, acaba se tornando o elo mais vulnerável da cadeia e lidando diariamente com tal problemática.

Palavras-chave: Tecnologias; Educação; Equidade.

\section{The use of educational technologies and the teaching methodologies used}

\begin{abstract}
The development of this article aims to discuss and bring to light the use of new educational technologies and, therefore, the teaching methodologies used. Thus, it is intended to establish a parallel between such technologies and the teaching methodologies used, so that we can see if there was an egalitarian development or if both are out of step, that is, the teaching methods used in the classroom, currently, are they able to assimilate and follow the advancement of technologies? This discussion about technologies as didactic means in education is extremely important, however, the school is not always able to keep up with technological developments. But, therefore, technologies are part of the current context and education should be used favorably. This article aims to demonstrate the importance of using communication technologies in education in search of better learning results. The research also brings up reflections on the use of technologies, and constructive criticisms in relation to the insertion of technological innovation without training for education professionals. Thus, the teacher, who is an important actor in this technological educational process, and is directly involved with the student in the teaching and learning process, ends up becoming the most vulnerable link in the chain and dealing with this problem on a daily basis
\end{abstract}

Keywords: Technologies; Education; Equity

Topic: Tecnologia, Educomunicação e Cibercultura

Reviewed anonymously in the process of blind peer
Received: $\mathbf{1 0 / 0 7 / 2 0 2 0}$

Approved: $\mathbf{2 0 / 1 1 / 2 0 2 0}$
Jailson Mauricio Pinto (iD)

Centro Universitário Leonardo da Vinci, Brasil

http://lattes.cnpq.br/5630364581431753

http://orcid.org/0000-0002-4051-0051

jailsonecop@hotmail.com

Douglas Vicente do Carmo Lima

Universidade Federal do Espírito Santo, Brasil

http://lattes.cnpq.br/8496236068852285

biologia14vicente@gmail.com

Ivani Vieira Damaceno

Universidade Federal do Espírito Santo, Brasil

http://lattes.cnpq.br/7230901191155082

http://orcid.org/0000-0002-7140-7241

ivanivida@gmail.com.br
Referencing this:

PINTO, J. M.; LIMA, D. V. C.; DAMACENO, I. V.. O uso das tecnologias educacionais e as metodologias de ensino utilizadas. Humanum Sciences, v.2, n.2, p.56-62, 2020. DOI:

http://doi.org/10.6008/CBPC2674-6654.2020.002.0005 


\section{INTRODUÇÃO}

Antes de entrarmos no assunto propriamente, é importante que se destaque que o termo 'novas tecnologias' é muito relativo, pois é cada vez mais constante e veloz o desenvolvimento tecnológico e cultural da humanidade. Dessa forma, considerando que há uma defasagem entre a inovação tecnológica e o seu uso, nesse caso, na sala de aula, até quando podemos considerá-la nova tecnologia, se nesse lapso de tempo certamente algo mais inovador já foi desenvolvido?

Outro ponto importante que se deve salientar está relacionado à origem das novas tecnologias, que eram desmembradas entre Tecnologias da Informação, ligada ao mundo da informática, e associada a quaisquer conhecimentos, procedimento ou meio utilizado para produzir, difundir, transmitir, classificar, armazenar, gravar, codificar-decodificar, interpretar as informações, e Tecnologias Audiovisuais na educação, que como origem o uso de projetores e aparelhos sonoros. A TV usada para fins educacionais e o uso dos videocassetes em grande escala produziram um grande avanço na utilização de instrumentos audiovisuais e verbo-icônicas no ambiente escolar. Atualmente, uma nova concepção é utilizada, a Multimídia, que predispõe a integração dos meios, códigos e linguagens anteriormente citados.

No atual cenário em que estamos vivendo, os profissionais da educação tiveram que se reinventar, utilizando os diversos meios de comunicação para ir à busca de contato com os estudantes. A Pandemia do Coronavírus, trouxe à tona a necessidade de autoaprendizagem por parte desses profissionais. Atuando com os mais diferentes aplicativos, como WhatsApp, Zoom, Meet, Microsoft Teams, redes sociais etc.

No ambiente educacional, a inserção da inovação tecnológica, se mostra, muitas vezes, inadequado. Alguns motivos dessa falha se dão pela falta de instrução do próprio professor, pela falta de assistência dos órgãos educacionais e pela infraestrutura precária; com tecnologias superadas e sucateadas. Dessa forma, o professor, que é ator importante nesse processo educacional tecnológico, e está diretamente envolvido com o aluno no processo de ensino e aprendizagem, acaba se tornando o elo mais vulnerável da cadeia e lidando diariamente com tal problemática.

Por isso é preciso que o docente passe por um processo de formação que lhe possibilite condições de obter conhecimento sobre as tecnologias, para que possa entender, compreender e integrar em sua prática pedagógica. Em sua formação, poucos são os docentes capacitados para usarem a tecnologia a favor da educação. Assim, ainda é comum encontrarmos profissionais que tem receio de usarem os meios tecnológicos por temerem ser substituídos por máquinas. Claro que os meios tecnológicos por si só não findam o processo educacional, são uma oportunidade para o professor rever sua metodologia de ensino e facilitar o aprendizado do educando.

O professor precisa ter competências necessárias ao seu papel, mediando e interagindo com os alunos, utilizando novos recursos tecnológicos, demonstrando a importância de mudança no planejamento pedagógico. Dessa forma, para atender a demanda de inovação tecnológica, o docente deverá colocar a educação cada vez mais próxima da vivência do aluno, integrando-o a uma sociedade em plena mutação 
O aprendizado é mais consistente, ou seja, tem maior significância quando 'colocamos a mão na massa', por isso, o educando deve ser estimulado a construir algo do seu interesse, usando tecnologias adequadas para uma aprendizagem mais significativa.

Cabe ao educador perceber e adequar sua metodologia de ensino as novas demandas da sociedade. Assim, devemos repensar sobre o educador que utiliza os recursos tecnológicos como meros transmissores de informação, deixando o aluno passivo no processo de aprendizagem, sendo um profissional novo com práticas velhas, pois utiliza a tecnologia como recurso pedagógico sem permitir ou provocar que seu aluno, através da tecnologia, construa o seu próprio conhecimento.

As tecnologias educacionais devem estar presentes no espaço escolar como meio de integração de conhecimentos, sendo utilizados por professores e alunos de forma democrática, não repressiva, mas com cooperação entre ambos, oportunizando uma troca mútua de informações e construção de um conhecimento sólido, tanto para professores, como alunos.

\section{DISCUSSÃO TEÓRICA}

\section{Educação na sociedade da informação}

Vivemos em uma época considerada como a era do conhecimento ou a sociedade do conhecimento, sobretudo em decorrência dos processos de informatização e globalização. $\mathrm{O}$ armazenamento de grandes volumes de informações permite o acesso e a pesquisa de maneira simples e fácil, conectando o globo por inúmeras teias.

Pela Internet, a partir de qualquer sala de aula do planeta, pode-se acessar inúmeras bibliotecas em muitas partes do mundo. As novas tecnologias permitem acessar conhecimentos transmitidos não apenas por palavras, mas também por imagens, sons, fotos, vídeos (hipermídia), etc. Nos últimos anos, a informação deixou de ser uma área ou especialidade para se tornar uma dimensão de tudo, transformando profundamente a forma como a sociedade se organiza. Pode-se dizer que está em andamento uma Revolução da Informação, como ocorreram no passado a Revolução Agrícola e a Revolução Industrial. (GADOTTI, 2000)

Nesse contexto, podemos perceber que as novas tecnologias propiciaram oportunidades para a abertura de espaços para o conhecimento que vão além da escola, pois atualmente o local de trabalho, a residência e o espaço social, de maneira abrangente, tornaram-se ambientes educativos. Dessa forma, a aprendizagem à distância destaca-se, angariando um número muito grande de adeptos dessa modalidade de ensino. Corroborando com esta ideia, Gadotti (2000) afirma que os espaços de formação têm uma ótima oportunidade de oferecer uma maior democratização da informação e do conhecimento e, por conseguinte, menos distorção e menos manipulação, menos controle e mais liberdade. É uma questão de tempo, de políticas públicas adequadas e de iniciativa da sociedade.

Nesse contexto, com a criação desse novo espaço de aprendizagem, compartilhamento de conhecimentos e formação continuada, novas metodologias de ensino devem ser pensadas e enquadradas a realidade vigente, cabendo aos docentes a responsabilidade de adequar as novas tecnologias com um ensino de excelência. 
Na sociedade da informação, a escola deve servir de bússola para navegar nesse mar do conhecimento, superando a visão utilitarista de só oferecer informações "úteis" para a competitividade, para obter resultados. Deve oferecer uma formação geral na direção de uma educação integral. O que significa servir de bússola? Significa orientar criticamente, sobretudo as crianças e jovens, na busca de uma informação que os faça crescer e não embrutecer. (GADOTTI, 2000)

Para que a escola alcance os objetivos supracitados, deverá repensar o seu projeto, priorizando a inovação. Além disso, deve fazer um planejamento de médio e longo prazo, refletindo, principalmente, sobre a reestruturação escolar, enfim tornar-se uma escola cidadã.

A escola está desafiada a mudar a lógica da construção do conhecimento, pois a aprendizagem agora ocupa toda a nossa vida. E porque passamos todo o tempo de nossas vidas na escola - não só nós, professores - devemos ser felizes nela. A felicidade na escola não é uma questão de opção metodológica ou ideológica, mas sim uma obrigação essencial dela. (GADOTTI, 2000)

Sendo assim, por intermédio de uma escola inovadora e cidadã, em conjunto com docentes com visões emancipadoras, haverá não haverá tão somente a transformação da informação em conhecimento, mas também, e principalmente, a formação de cidadãos críticos, capazes de participar ativamente da sociedade contemporânea.

\section{Tecnologia e escola, um 'delay' na utilização dos recursos.}

O desenvolvimento, cada vez mais rápido, da tecnologia tem influenciado todas as áreas do conhecimento, implicando, como não poderia ser diferente, em mudanças na área da educação. A qualidade da educação, geralmente centrada nas inovações curriculares e didáticas, não pode se colocar à margem dos recursos disponíveis para levar adiante as reformas e inovações em matéria educativa, nem das formas de gestão que possibilitam sua implantação. No entanto,

As inovações em educação costumam ser adotadas em ritmo muito lento, a ponto de se constatar algumas vezes que determinados novos aparelhos e suportes multimídia já estão desaparecendo do mercado, substituídos por outros, quando no mundo da educação ainda se está discutindo a sua possível incorporação como meios didáticos. O ritmo frenético no desenvolvimento das tecnologias de informação e comunicação praticamente impossibilita a indispensável reflexão sobre seus efeitos. (MARTíN, 1996)

O grande problema ocasionado pelo atraso de uso das tecnologias nas escolas está relacionado ao não acompanhamento da evolução da sociedade, na qual deveria estar completamente integrada, podendo ocasionar, por conta disso, desmotivação e distanciamento dos discentes. Nesse contexto, podemos incluir na problemática em questão, que a metodologia de ensino, presa em conceitos ultrapassados, e a falta de preparo dos docentes, ainda distantes de um conhecimento tecnológico adequado, contribuem, ainda mais, para a falta de interesse dos alunos no que se refere ao ambiente escolar. Dessa forma, segundo Martín (1996): “As instituições de educação formal poderiam ser consideradas, desta perspectiva, mais como obstáculos do que como agentes facilitadores do desenvolvimento da criança e da sociedade em geral".

Seguindo esse pensamento, podemos observar, também, que o atraso na evolução da educação é muito preocupante no que tange tecnologia, existindo uma grande defasagem na educação recebida entre os habitantes dos países desenvolvidos e dos países em desenvolvimento. Dessa forma, é necessário que ocorra um equilíbrio na utilização dessas tecnologias para que ocorra uma maior equidade de oportunidades. 
Na sociedade da informação, como se tornou habitual classificá-la nos últimos tempos, o mercado de trabalho necessita de mão de obra especializada no manejo dos sistemas de informação e de comunicação, e se considera como obrigação dos sistemas educativos atender a tais demandas, incorporando em seus programas de educação formal a utilização de novas tecnologias. (MARTíN, 1996)

Dessa forma, chegamos a um paradoxo, se por um lado corremos o risco dos sistemas educacionais se tornarem superados em relação ao desenvolvimento tecnológico, por absorverem de forma lenta os frutos da tecnologia, por outro também podemos embarcar em um caminho que não propiciaria ganho educacional, pois, indubitavelmente, correríamos perigo de aceitar e implementar as novas tecnologias nas nossas escolas por um apelo comercial, sem nos questionar sobre as consequências ideológicas ou sobre seu impacto no processo de ensino e aprendizagem.

Não podemos esquecer que a tecnologia, além de seu aspecto liberador, pode ser também uma das mais poderosas armas de repressão cultural e ideológica; se pode diminuir as diferenças culturais entre os povos, pode também aumentá-las; se possibilita uma comunicação inovadora no ensino capaz de gerar aprendizagens significativas, pode também perpetuar pedagogias autoritárias e unidirecionais (MARTíN, 1996).

Por fim, vislumbra-se que na escola, num futuro próximo, as inovações tecnológicas estejam, dentro daquilo que é viável e pertinente completamente inseridas e funcionais. Dessa forma, os docentes, adequados a essa nova realidade, poderão de fato, por intermédio de equipamentos modernos, ministrarem aulas que permitirão, com mais facilidade, a interatividade, a participação, a intervenção e a multidisciplinaridade, ampliando a sensorialidade e rompendo, definitivamente, com a separação emissor/receptor.

\section{Novas tecnologias: aprendizado contínuo}

“Como professor crítico, sou um 'aventureiro' responsável predisposto à mudança, à aceitação do diferente" (FREIRE, 2011). Para Freire em Pedagogia da Autonomia, o professor deve ter consciência de que somos inacabados, só assim estaremos sempre em busca de novos ensinamentos.

O mundo globalizado está conectado, os saberes são proporcionados em larga extensão, às tecnologias hoje existentes trazem a necessidade de atualização dos docentes, já que a até pouco tempo essas tecnologias não eram de fácil acesso como acorre hoje.

Pierre Furter (1992) resumiu a necessidade do constante aperfeiçoamento educacional da seguinte forma:

(...) o primeiro imperativo que deve preencher a Educação Permanente é a necessidade que todos nós temos de sempre aperfeiçoar a nossa formação profissional. (...) O domínio de uma profissão não exclui o seu aperfeiçoamento. Ao contrário. Será mestre quem continuar aprendendo. (FURTER, 1992)

Com tantas mudanças rápidas e contínuas que estamos presenciando, existe uma necessidade de capacitação continuada, pois não basta só o conhecimento adquirido no período escolar de formação, há uma necessidade de atualização continua. Para Haddad (2007) é próprio do ser humano essa busca constante de aprendizado, sempre querendo saber mais e conhecer mais. 
Haddad (2007) também defende a educação continuada. "Outro campo importante de prática em ações de Educação Continuada diz respeito a um amplo movimento que une a valorização e o respeito dos direitos da pessoa humana aos processos de desenvolvimento" (HADDAD, 2007).

Os docentes contam hoje com várias ferramentas de ensino, que bem aproveitada poderá proporcionar um ensino de qualidade e interessante, garantindo um maior envolvimento dos alunos na aula, pois estará utilizando técnicas que os alunos têm afinidade.

Nesse contexto vivenciamos a importância dos docentes estarem capacitando-se, para agregarem as novas tecnologias com os métodos de ensino, adotando essas ferramentas como recurso pedagógico.

De acordo com Freire (2011), a construção do ser se faz através de influência externa, social e genética. O professor deve se preparar para essas mudanças, pois estamos vivendo em uma sociedade que vive conectada pela internet, utilizando várias ferramentas disponibilizadas pela rede, recebendo todo tipo de informação, os docentes que estão acompanhando as inovações tecnológicas poderão aproveitar essas ferramentas para tornar mais viva e dinâmica suas aulas.

\section{CONCLUSÕES}

Quando os seres humanos desenvolveram a capacidade de falar deram um grande salto na evolução, pois a partir desse momento uma rede de comunicação foi estabelecida, trazendo ganhos notórios. O poder de transmissão do conhecimento, nossa principal característica, trouxe enorme vantagem em relação às outras espécies, e certamente foi determinante para o sucesso da raça humana.

Atualmente, vivenciamos outro grande momento da humanidade, pois a comunicação que nos propiciou vantagem, agora pode ser feita de maneira mais abrangente, fortalecendo, ainda mais, nossas características sociais.

Dessa forma, com base na discussão supracitada sobre o uso das tecnologias educacionais e as metodologias de ensino empregadas, podemos perceber que as tecnologias contemporâneas nos forneceram uma gama enorme de possibilidades no que tange à educação, pois com os processos de informatização e globalização o acesso a volumes imensuráveis de informações se tornou simples e fácil. Além disso, as tecnologias propiciaram o 'encurtamento' das distâncias no nosso planeta, conectando o globo por diversas teias de comunicações.

Nesse contexto, acompanhando o desenvolvimento, os espaços educacionais, antes restritos a estrutura física da escola, ganharam novos significados, pois a tecnologia oportunizou novos ambientes de aprendizagem, tais como, o local de trabalho e a residência, entre outros espaços sociais. No entanto, as escolas atuais aliadas aos novos espaços de aprendizagem necessitam de projetos e metodologias adequadas para que possam realmente funcionar como locais de formação de cidadãos pensantes e críticos.

Outro ponto discutido no trabalho abrangeu o atraso na utilização dos recursos tecnológicos no ambiente escolar, onde se colocou em pauta que as inovações tecnológicas na área educacional se dão de forma vagarosa, causando um 'delay' entre as tecnologias disponíveis no mercado e as que estão em uso nas escolas. Nesse contexto, citamos que tal problemática pode desmotivar os discentes, normalmente 
acostumados a utilizar as tecnologias mais atuais. Aliado a essa defasagem, também foi exposto que as metodologias, muitas vezes, arcaicas e a falta de preparo dos docentes também contribuem para o desinteresse dos alunos pelo ambiente escolar. Dessa forma, com o intuito de amenizar os problemas mencionados, foi vislumbrado que na escola do futuro as tecnologias devem estar mais presentes no ambiente escolar, da mesma forma que os docentes também devem estar adequados à realidade, possibilitando, assim, aulas motivadoras e significativas para os discentes.

Por fim, ressaltou-se que as novas tecnologias favorecem um aprendizado contínuo, onde foi exposto que no mundo globalizado, altamente conectado, as informações e saberes estão totalmente disponíveis, exigindo, por conta disso, uma atualização constante dos docentes, pois até pouco tempo o acesso a tantas informações era impensado. Nesse sentido, com a velocidade que as mudanças ocorrem na atualidade, praticamente nos obriga a realizarmos capacitações continuadas, a fim de buscarmos um constante aprendizado. Além disso, tais capacitações são fundamentais para garantir um maior interesse dos discentes nas aulas, pois por intermédio de novas ferramentas pedagógicas de ensino os docentes estarão aptos a ministrar aulas mais interessantes e atrativas.

Sendo assim, é indispensável, na sociedade do conhecimento, que o professor esteja preparado a continuar intermediando as informações e, dessa forma, nortear a construção do conhecimento dos discentes. No entanto, para que esse elo, fundamental para a sociedade, funcione adequadamente, tornase essencial que esteja completamente capacitado para exercer o seu papel.

\section{REFERÊNCIAS}

FREIRE, P.. Pedagogia da autonomia: saberes necessários à prática educativa. São Paulo: Paz e Terra, 2011.

FURTER, P.. Educação e vida. 12 ed. Petrópolis: Vozes, 1992.

GADOTTI, M.. Perspectivas atuais da educação. São Paulo em Perspectiva, v.14, n.2, p.3-11, 2000.
HADDAD, S.. A Educação Continuada e as políticas públicas no Brasil. Revista de Educação de Jovens e Adultos, v.1, p.27-38, 2007.

MARTíN, A. G.. Educação e novas tecnologias. Colatina: IFES, 1996.

A CBPC - Companhia Brasileira de Produção Científica (CNPJ: 11.221.422/0001-03) detém os direitos materiais desta publicação. Os direitos referem-se à publicação do trabalho em qualquer parte do mundo, incluindo os direitos às renovações, expansões e disseminações da contribuição, bem como outros direitos subsidiários. Todos os trabalhos publicados eletronicamente poderão posteriormente ser publicados em coletâneas impressas sob coordenação da Sapientiae Publishing, da Companhia Brasileira de Produção Científica e seus parceiros autorizados. Os (as) autores (as) preservam os direitos autorais, mas não têm permissão para a publicação da contribuição em outro meio, impresso ou digital, em português ou em tradução. 